Crucial disputes about the funding of science, or on the influence of industry on agency actions supposedly based on science, simply will not come within the Supreme Court's reach. Its decisions about abortion and sexual freedom will influence public health, but will not, on either side, involve much science. I am unhappy about the Bush administration's general attitude towards science and its selection of Supreme Court justices, as two separate harms; a conservative counter-revolution on the Supreme Court would change the United States (for the worse, in my view) but is unlikely to have a major effect on science.

Will that counter-revolution take place? Observers have proclaimed its coming since at least 1969, when Chief Justice Burger replaced
Chief Justice Warren - Toobin himself details other such failed reversals in the past 20 years. The Supreme Court's future course depends largely on its future members, who in turn depend on future presidents and senators - and the public opinion to which they all, in part, respond. It also depends on the current 'nine' and how (not if) they change during their years on the court.

Toobin's book is an excellent introduction to today's Supreme Court, but readers must bear in mind that part of the "secret world" of the court is its own future course.

Henry T. Greely is professor of law, professor (by courtesy) of genetics and director of the Center for Law and the Biosciences, Stanford University, California 94305-8610, USA.

\title{
The real 'theory of everything'
}

\section{Four Laws that Drive the Universe \\ by Peter Atkins \\ Oxford University Press: 2007. 128 pp. $\$ 19.95$}

\section{Mark Haw}

Ask a science graduate to name their favourite subject, and few will say thermodynamics. My own undergraduate memories of the subject include a baffling proliferation of nineteenthcentury science grandees - James Clerk Maxwell, Lord Kelvin and James Prescott Joule - some exhaustively squeezed gases and a forest of incomprehensible partial derivatives I couldn't imagine how to measure.

Thermodynamics ought to be the cornerstone of any scientist's understanding of nature. Forget superstrings and grand unified theories: thermodynamics is the original 'theory of everything. Or perhaps the 'theory of what everything does and how it does it'. Thermodynamics explains the transformation of energy, and nothing happens without that.

In his new book Four Laws that Drive the Universe, Peter Atkins aims squarely at the fundamental logical and physical structure of thermodynamics. Atkins's systematic foundations should go a long way towards easing confusion about the subject. He dissects the laws one by one, tying each firmly to its partner fundamental quantity, be it temperature, internal energy or entropy.

There is no shortage of books on thermodynamics - indeed Atkins himself is a veteran of this particular publishing niche. The thing that distinguishes this quasi-textbook (for popular science it definitely isn't) from the others is its almost complete absence of mathematics. Hang on, where are the partial derivatives? Where are Maxwell's relations? This is Atkins's masterstroke: without the encumbrance of equations that are never actually going to be applied, readers may begin to grasp what energy and entropy are really about.

Therein lies a difficulty: should you need to derive the back legs off the thermodynamic donkey, Four Laws would have to be supported by a more traditional text. If deep understanding is what you want, this book is the better choice. There is a need in many fields, from atomic physics to cell biology, for books with a similar brief to this one. Too many prime their readers with facts and figures to avoid the challenge of properly illuminating the underlying concepts.

And just suppose you were setting out on such a crusade, to promote understanding of

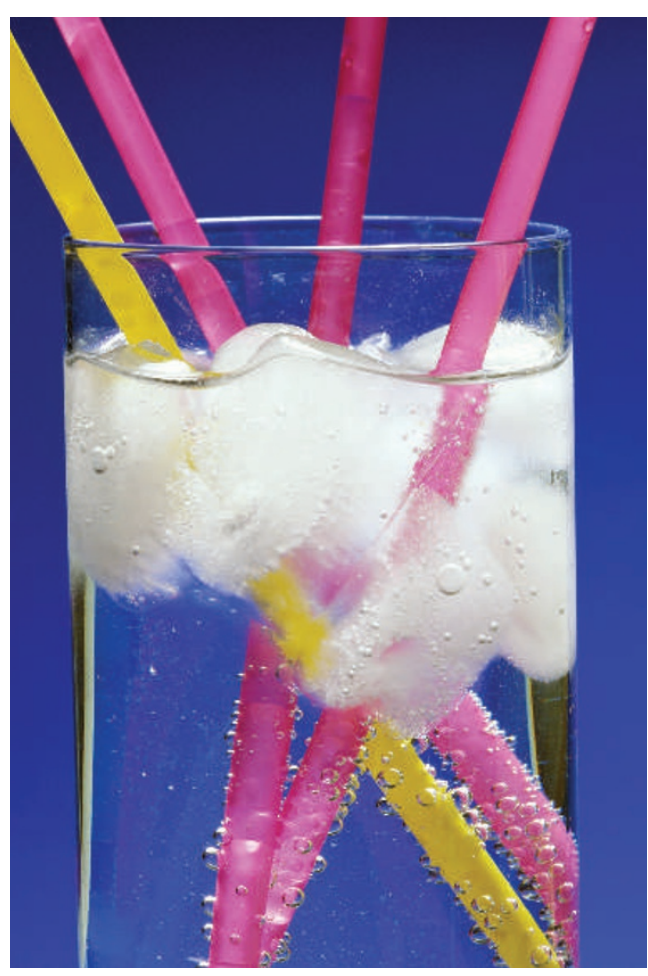

Entropy increases as order collapses in melting ice. scientific ideas as an alternative to feverishly memorizing the technical details in the hope of passing an exam or sounding clever at a conference - then thermodynamics is a good place to start.

The development of thermodynamics in the nineteenth century was the most wide-reaching and fundamental advance since Newton's mechanics. It underpinned (albeit some time after the event) the Industrial Revolution, and led the way to statistical mechanics (and hence to statistical quantum mechanics) and to an understanding of phase behaviour, chemical reactions, the astrophysics of stars...to everything, in other words.

Or almost everything. Atkins never treads beyond the limitations of nineteenth-century thermodynamics, which can be summed up in three words - equilibrium, isolation and big. His 'four laws' work for systems at (or very near) equilibrium, systems isolated from (or at least connected in a very controlled way to) their surroundings, and systems that are, well, big. Big enough that the averages of macroscopic thermodynamics tell the whole story, big enough that fluctuations from the average don't matter.

A flavour of the subject beyond these limitations would have rounded out the book — highlighting the striking fact that, in this centenary year of the death of its great pioneer Lord Kelvin, thermodynamics is still very much in business. For instance, the latest research into the energetics of small systems, such as proteins, is potentially revolutionary. Proteins do the same job for life that steam engines did for Victorian industry. Unlike a railway engine, however, the cell is a profoundly non-equilibrium place. And proteins are not isolated but inextricably bound to the world around them, inescapably prey to brownian motion.

Understanding the microscopic, nonequilibrium, open-system thermodynamics of these 'life engines' could usher in fascinating discoveries: how life works as a physical process, how we might borrow life's technology to make our own nanoengines, and how we might transform medicine by replacing broad-spectrum chemical cocktails with medical engineering of proteins. All this requires twenty-first-century developments in thermodynamics that are no less revolutionary than the nineteenth-century theory.

Even without this excursion into the future, Atkins has written an engaging book, just the right length (and depth) for an absorbing, informative read. Those for whom the word 'entropy' still induces cold sweats may at last get a proper glimpse of the real 'theory of everything'.

Mark Haw lectures in the School of Chemical and Environmental Engineering, University of Nottingham, University Park, Nottingham NG7 2RD, UK. He is author of Middle World: The Restless Heart of Matter and Life. 